NIST Technical Note 1948

\title{
What's in a butt? Environmental contamination from airborne cigarette butt emissions
}

\author{
Mengyan Gong \\ Shahana Khurshid \\ Dustin Poppendieck
}

This publication is available free of charge from:

https://doi.org/10.6028/NIST.TN.1948

National Institute of 


\title{
What's in a butt? Environmental contamination from airborne cigarette butt emissions
}

\author{
Mengyan Gong \\ Shahana Khurshid \\ Dustin Poppendieck \\ Engineering Laboratory
}

This publication is available free of charge from:

https://doi.org/10.6028/NIST.TN.1948

January 2017

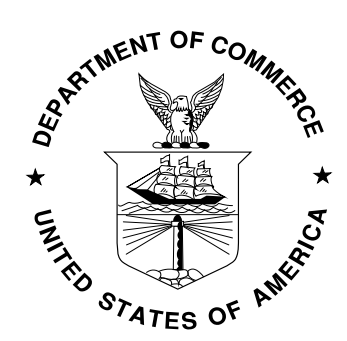

National Institute of Standards and Technology 
Certain commercial entities, equipment, or materials may be identified in this document in order to describe an experimental procedure or concept adequately. Such identification is not intended to imply recommendation or endorsement by the National Institute of Standards and Technology, nor is it intended to imply that the entities, materials, or equipment are necessarily the best available for the purpose.

National Institute of Standards and Technology Technical Note 1948 Natl. Inst. Stand. Technol. Tech. Note 1948, 9 pages (January, 2017) CODEN: NTNOEF

This publication is available free of charge from: https://doi.org/10.6028/NIST.TN.1948 
Cigarette butts are ubiquitous in the environment. Globally, five trillion cigarette butts are generated every year (Smith and Novotny 2011). Cigarette butts are one of the most common forms of litter discarded onto beaches, bus stops, roads, streets, parks, and many other public places (Novotny et al. 2011). They are also commonly found in ashtrays in homes, cars, and public places (Novotny et al. 2011). Most cigarette filters (a major part of cigarette butts) are made of cellulose acetate, which is photodegradable, but not easily biodegradable (Puls et al. 2011). Hence, they may persist in the environment for more than 10 years. Although many measures have been taken to prevent or mitigate cigarette butt pollution, none have been effective (Smith and Novotny 2011).

More important than being unsightly litter, chemicals can emit or leach from cigarette butts and impact human health and the environment. Instances of children ingesting cigarette butts have been reported, which can cause toxic effects, including vomiting within twenty minutes (Novotny et al. 2011). The impacts of cigarette butts on animals have been reported more widely, e.g., genotoxicity in house finches that use cellulose acetate as lining material in nests, shorter life span and higher mortality rates during developmental stages for mosquitos that have hatched in water contaminated by cigarette butts, as well as mortality and behavioral modifications in snails exposed to cigarette butt leachate in seawater (see references within Poppendieck et al. 2016).

Given the ubiquitous nature of cigarette butts and the potential for causing adverse environmental impacts, a literature research was conducted to review studies on cigarette butt airborne emissions using Web of Science and Compendex Engineering Village databases with “cigarette butt*” “cigarette filter*” “cigarette tip*” “tobacco filter*” as keywords on January 2016. Combining search results from the two databases, 2,381 papers were identified. A detailed review of these papers has been published by Poppendieck et al. (2016). In summary, none of the 2,381 papers studied airborne emissions from cigarette butts under typical indoor or outdoor environment conditions. Four papers reported the emission of chemicals from cigarette butts into headspace vials at elevated temperatures $\left(>80^{\circ} \mathrm{C}\right)$. However, the results of these studies cannot be translated to real environments because the high temperatures may result in the emission of chemicals that are not likely to be emitted under normal indoor or outdoor conditions. Therefore, the mass of chemicals emitted in these studies cannot be used to calculate emission rates. Four of the reviewed papers studied the 
chemical emission rates from cigarette butts into water and showed that these emissions can be a short term phenomenon. Moerman and Potts (2011) reported that more than half of the metals in cigarette butts were leached within one day in aqueous solutions. In addition, twenty-two papers measured chemicals retained in cigarette butts using solvent extraction methods. These studies describe the kinds of chemicals retained in cigarette butts, but not the chemical emission rates into the environment.

The chemicals reported in these thirty papers from cigarette butt emission and extraction studies are summarized in Table 1, and include alcohols, alkaloids, aromatic amines, carbonyls, hydrocarbons, insecticides, metals, nitrosamines, nitro polycyclic aromatic hydrocarbons, polycyclic aromatic hydrocarbons, phenols, phthalates, pyrazines, pyrroles, terpenes, and terpenoids. Generally, each study only examined a small number of chemicals. About 130 chemicals in all have been reported to be present in cigarette butts. These chemicals are not unique to cigarette butts, and are often the same chemicals detected in mainstream smoke and sidestream cigarette smoke. However, many more chemicals (40 000 to 100 000) (Dalluge et al. 2002) have been identified in cigarette smoke, some of which could potentially be retained in cigarette butts and subsequently emitted into the environment depending on the environmental conditions and chemical properties.

Overall, cigarette butt emissions are just beginning to be understood, with more comprehensive studies needed to examine the extent of these emissions. These emission rate studies need to cover a wide range of chemicals, with a focus on chemicals with higher toxicity. In addition, studies are needed to quantify changes in emission rates over time under different conditions. These studies will be challenging due to the different emission characteristics of the chemicals and the variety of influencing factors that can affect emissions from cigarette butts, such as brand, filter material, butt length, degradation, ambient temperature, airflow around the cigarette, ventilation through the cigarette, number of puffs drawn, and smoking method.

Given the lack of information on airborne emissions from cigarette butts under typical indoor or outdoor conditions, we conducted some preliminary experiments to measure the emissions from cigarette butts in headspace vials. A freshly generated cigarette butt and a cigarette butt aged on the ground for an unknown period of time were incubated in headspace vials at $35^{\circ} \mathrm{C}$ (this temperature is closer to ambient conditions than headspace temperatures 
in previous studies). The vials were then sampled with Tenax-TA tubes and analyzed using Gas Chromatograph-Mass Spectroscopy (GC-MS). Both cigarette butts emitted more than 100 chemicals. For the freshly generated cigarette butt, the chromatogram peaks with the top five largest areas were identified as d-limonene, toluene, pyridine, benzene and styrene. For the cigarette butt found on ground, the top five peaks were different from the freshly generated butt: nicotine, 3-methyl-pyridine, furfural, pyridine, and methyl-pyrazine. The results indicated that short term and long term emissions from cigarette butts may differ, and different chemicals need to be considered at different stages of emission. Note that these two butts are only used to investigate methods and get a preliminary idea on the cigarette butt airborne emission, and are not necessarily representative of all the cigarette butts in the real world. For further study, more cigarette butts will be measured and we will quantify airborne emissions of selected chemicals from cigarette butts using headspace analysis after they have been exposed for specific periods of time to a variety of environmental conditions. This will enable us to examine the influence of temperature, relative humidity, surrounding flow rate, photo-degradation, and water content on airborne emissions from cigarette butts.

\section{Disclaimer}

Certain trade names or company products are mentioned in the text to adequately specify the experimental procedure and equipment used. In no case does such identification imply recommendation or endorsement by the National Institute of Standards and Technology, nor does it imply that the equipment is the best available for the purpose.

\section{Acknowledgement}

The authors thank the U.S. Food and Drug Administration for funding for the literature review through Interagency Agreement \#244-15-9012.

\section{References}

Dalluge J, Van Stee KKO, Xu X, Williams J, Beens J, Vreuls RJJ, Brinkman UAT. 2002. Unravelling the composition of very complex samples by comprehensive gas chromatography coupled to time-of-flight mass spectrometry: Cigarette smoke. $J$ Chromatogr A 974: 169-184.

Moerman JW, Potts GE. 2011. Analysis of metals leached from smoked cigarette litter. Tobacco Control 20: I30-I35. 
Novotny TE, Hardin SN, Hovda LR, Novotny DJ, McLean MK, Khan S. 2011. Tobacco and cigarette butt consumption in humans and animals. Tobacco Control 20: I17-I20.

Poppendieck D, Khurshid S, Emmerich S. 2016. Measuring airborne emissions from cigarette butts: literature review and experimental plan. Available from: http://dx.doi.org/10.6028/NIST.IR.8147.

Puls, J, Wilson SA, Holter D. 2011. Degradation of cellulose acetate-based materials: A review. J Polym Environ 19(1): 152-165.

Smith EA, Novotny TE. 2011. Whose butt is it? Tobacco industry research about smokers and cigarette butt waste. Tobacco Control 20: I2-I9. 
Table 1 Summary of chemicals detected in cigarette butt emission and extraction studies ${ }^{a}$

\begin{tabular}{|c|c|c|c|}
\hline Media & $\begin{array}{l}\text { Number } \\
\text { of } \\
\text { Papers }\end{array}$ & $\begin{array}{l}\text { Chemical } \\
\text { Groups detected }\end{array}$ & Chemical Names \\
\hline \multirow[t]{6}{*}{ Air } & 4 & 6 Alcohols & $\begin{array}{l}\text { ethanol, 2-furfuryl alcohol, isopropanol, methanol, } \\
\text { 1-methoxy-2-propanol, 1-ethoxy-2-propanol }\end{array}$ \\
\hline & & 21 Carbonyls & $\begin{array}{l}\text { acetol, acetone, butyl acetate, cyclohexanone, } \\
\text { 2-pentanone, n-propanol, n-propyl acetate } \\
\text { cyclopentanone, 2-cyclopentenone, 2-methylcyclo pentenone, } \\
\text { 4-methyl-2-pentanone, methyl n-butyl ketone, n-butyl alcohol } \\
\text { ethyl acetate, 3-furaldehyde, 2-furaldehyde, isopropyl acetate, } \\
\text { protoanemonin, acetol formate, 3-methyl-2-cyclopentenone, } \\
\text { 2,3-pentanedione }\end{array}$ \\
\hline & & 11 Hydrocarbons & $\begin{array}{l}\text { ethyl benzene, benzene, 3,3-dimethyl-1-butene, pyridine, } \\
\text { cyanobenzene, cyclooctatetraene, isocapronitrile, toluene, } \\
\text { p-xylene, m-xylene, o-xylene }\end{array}$ \\
\hline & & 2 Pyrazines & pyrazine, 2-methylpyrazine \\
\hline & & 4 Pyrroles & $\begin{array}{l}\text { n-methylpyrrole, pyrrole, 3-methylpyrrole, } \\
\text { 2-methylpyrrole }\end{array}$ \\
\hline & & 1 Terpene & limonene \\
\hline \multirow[t]{8}{*}{ Water } & 4 & 1 Alkaloid & 7-carbaldehyde camptothecin \\
\hline & & $\begin{array}{l}7 \text { Aromatic } \\
\text { Amines }\end{array}$ & $\begin{array}{l}\text { nicotine, hexaconazole, imidocarb, cotinine, } \\
\text { 2-(pyridin-3-yl) pyrrolidine-1-carbaldehyde,sulfadoxine, } \\
\text { 5-(4,6-dichloropyridin-3-yl)-pyridine-1(2h)-carboxamidea }\end{array}$ \\
\hline & & 2 Carbonyls & $\begin{array}{l}\text { 5-(4-hydroxy pyridin-3-yl)-pyridine-1(2H)-carboxamide, } \\
\text { 7-keto-benzo(a)pyrene }\end{array}$ \\
\hline & & 8 Metals & $\begin{array}{l}\text { aluminum, barium, cadmium, lead, manganese, nickel*, strontium, } \\
\text { titanium }\end{array}$ \\
\hline & & 1 Nitrosamine & N-nitrosonornicotine \\
\hline & & $1 \mathrm{PAH}^{\mathrm{b}}$ & benzo(a)pyrene \\
\hline & & 3 Phenols & $\begin{array}{l}\text { rutin, 2,2-dimethyl-2,3-dihydrobenzofuran-7-ol, } \\
\text { 1,5-dihydroxy-anthraquinon }\end{array}$ \\
\hline & & 2 Terpenes & beta-carotene-4,4'-dione, xanthophylls \\
\hline \multirow[t]{10}{*}{ Solvent } & 22 & 8 Carbonyls & $\begin{array}{l}\text { acetone, formaldehyde, acetaldehyde, acrolein, propionaldehyde, } \\
\text { crotonaldehyde, 2-butanone, butyraldehyde }\end{array}$ \\
\hline & & 3 Insecticides & maleic hydrazide, chlorantraniliprole, imidacloprid \\
\hline & & 1Metalloid & arsenic \\
\hline & & 8 Metals & cadmium, chromium, copper, mercury, iron, lead, manganese, zinc \\
\hline & & 1 Nitrosamine & TSNAs $^{\mathrm{d}}$ \\
\hline & & $3 \mathrm{NPAH}^{\mathrm{c}}$ & 1,3-dinitronaphthalene, 9-nitroanthracene, nitrobenzene \\
\hline & & 6 PAHs & $\begin{array}{l}\text { anthracene, benzo[a]pyrene, benz[a]anthracene, } \\
\text { benzo[b]fluoranthene, fluoranthene, pyrene }\end{array}$ \\
\hline & & 8 Phenols & $\begin{array}{l}\text { catechol, hydroquinone, m-cresol, o-cresol, p-cresol, phenol, } \\
\text { resorcinol, rutin }\end{array}$ \\
\hline & & 3 Phthalates & $\begin{array}{l}\text { dibutyl phthalate, diisobutyl phthalate, } \\
\text { di(2-ethylhexyl) phthalate }\end{array}$ \\
\hline & & 1 Terpenoid & solanesol \\
\hline
\end{tabular}


a: The citations can be found in Poppendieck et al. (2006); b: polycyclic aromatic hydrocarbons; c: nitro polycyclic aromatic hydrocarbons; d: The specific chemicals of tobacco specific nitrosamines (TSNAs) are not available in the cited paper. 